\title{
Antifungal activity of synthetic naphthoquinones against dermatophytes and opportunistic fungi: preliminary mechanism-of-action tests
}

\author{
Maria do Perpetuo Socorro Borges Carriço Ferreira ${ }^{1}$, Mariana Filomena do Carmo Cardoso², \\ Fernando de Carvalho da Silva², Vitor Francisco Ferreira ${ }^{2}$, Emerson Silva Lima ${ }^{1}$ and João Vicente Braga Souza ${ }^{3^{*}}$
}

\begin{abstract}
This study evaluated the antifungal activities of synthetic naphthoquinones against opportunistic and dermatophytic fungi and their preliminary mechanisms of action. The minimum inhibitory concentrations (MICs) of four synthetic naphthoquinones for 89 microorganisms, including opportunistic yeast agents, dermatophytes and opportunistic filamentous fungi, were determined. The compound that exhibited the best activity was assessed for its action against the cell wall (sorbitol test), for interference associated with ergosterol interaction, for osmotic balance ( $\mathrm{K}^{+}$efflux) and for membrane leakage of substances that absorb at the wavelength of $260 \mathrm{~nm}$. All tested naphthoquinones exhibited antifungal activity, and compound IVS320 (3a,10b-dihydro-1H-cyclopenta [b] naphtho [2,3-d] furan-5,10-dione)-dione) demonstrated the lowest MICs across the tested species. The MIC of IVS320 was particularly low for dermatophytes (values ranging from 5-28 $\mu \mathrm{g} / \mathrm{mL}$ ) and Cryptococcus spp. (3-5 $\mu \mathrm{g} / \mathrm{mL}$ ). In preliminary mechanism-of-action tests, IVS320 did not alter the fungal cell wall but did cause problems in terms of cell membrane permeability (efflux of $\mathrm{K}^{+}$and leakage of substances that absorb at $260 \mathrm{~nm}$ ). This last effect was unrelated to ergosterol interactions with the membrane.
\end{abstract}

Keywords: Naphthoquinones, Antifungal activity, Mechanism of action

\section{Introduction}

The recent high incidence of fungal infections is due to the increased number of immunocompromised patients who are infected with HIV or have undergone organ transplantation or chemotherapy [1]. Although effective antifungal agents are currently available, side effects such as toxicity, drug interactions, inadequate pharmacokinetic properties and the development of resistance have been reported [2]. Therefore, new active entities that are safer, more potent and broad spectrum are highly desired as antifungal agents.

Among natural substances, naphthoquinones (found in bacteria, fungi, animals and plants) have attracted interest in recent years due to both their importance in vital biochemical processes and their several known biological activities, such as antitumor, antibacterial and antiviral [3].

\footnotetext{
* Correspondence: joao.souza@inpa.gov.br

${ }^{3}$ Instituto Nacional de Pesquisa.da Amazônia, Laboratório de Micologia, Manaus, AM, Brazil

Full list of author information is available at the end of the article
}

Indeed, a series of studies have demonstrated that naphthoquinone derivatives exhibit antifungal activity $[4,5]$. Additionally, the antifungal activity of four synthesized compounds was reported against six species of Candida isolated from the oral cavities of patients with removable prostheses [6].

In this work, the antifungal activities of the compounds 2,2-dimethyl-2,3-dihydronaphtho [2,3- $b]$ furan-4,9-dione, 2,2-dimethyl-2,3-dihydronaphtho $[1,2-b]$ furan-4,5-dione, 3a,10b-dihydro-1H-cyclopenta [b] naphtho [2,3-d] furan5,10-dione)-dione and 7,9a-dihydro-6bH-cyclopenta [b] naphtho [2,1-d] furan-5,6-dione were evaluated against 89 fungal cultures, including 29 opportunistic yeasts, 40 filamentous fungi and 20 opportunistic dermatophytes. The mechanism of action of the compound with the most effective antifungal activity was investigated using Candida albicans strain ATCC 36232. 


\section{Methods}

\section{Naphthoquinones}

The compounds used in this study were the naphthoquinones IVS320 (3a,10b-dihydro-1H-cyclopenta [b] naphtho [2,3-d] furan-5,10-dione)-dione), IVS322 (7,9a-dihydro6bH-cyclopenta [b] naphtho [2,1-d] furan-5,6-dione), nor- $\alpha$-lapachone (2,2-dimethyl-2,3-dihydronaphtho [2,3- $b$ ] furan-4,9-dione) and nor- $\beta$-lapachone (2,2-dimethyl-2,3dihydronaphtho $[1,2-b]$ furan-4,5-dione) (Figure 1). These compounds were synthesized by the Developing Biologically Active Molecules and Methods for Organic Synthesis research group, Department of Organic Chemistry, Universidade Federal Fluminense-UFF, as described by Freire et al. [6]. A stock solution ( $2 \mathrm{mg} / \mathrm{mL}$ ) of each compound was prepared and then diluted in RPMI 1640 (SigmaAldrich Co., St. Louis, MO, USA) to the required concentrations for the assays.

\section{Microorganisms}

Eighty-nine cultures (Table 1) from the Collection of Microorganisms belonging to the National Institute of Amazon Research-INPA were used in this study. The cultures were preserved in mineral oil, and subcultures were maintained in Sabouraud medium to ensure purity and viability until the testing was performed. A culture of C. albicans (36232) from the American Type Culture Collection (ATCC) was used as a control for the susceptibility testing and mechanism-of-action studies.

\section{Antifungal activity assay}

Minimum inhibitory concentration (MIC) assays were performed with the broth microdilution method, as described by the CLSI (Clinical and Laboratory Standards Institute) in documents M27-A2/CLSI [7] and M38-A [8]. Briefly, $100 \mu \mathrm{L}$ of each evaluated compound diluted in RPMI 1640 broth was added to 96-well microplates, with the final concentrations of the compounds ranging from
100 to $0.2 \mu \mathrm{g} / \mathrm{mL}$ (naphthoquinones) and from 64 to $0.06 \mu \mathrm{g} / \mathrm{mL}$ (ketoconazole). Next, $100 \mu \mathrm{L}$ of an inoculum containing $2.5 \times 10^{3}$ cells $/ \mathrm{mL}$ of opportunistic yeasts, $2.5 \times 10^{5}$ cells $/ \mathrm{mL}$ of dermatophytosis agents or $2.5 \times$ $10^{4}$ cells/mL of opportunistic filamentous fungi was added to the microplate. The microdilution plates were incubated at room temperature $\left(35^{\circ} \mathrm{C}\right)$ for 24 to 48 hours (opportunistic yeasts), 15 days (ringworm agents) or 3 days (opportunistic filamentous fungi). Visual readings were performed after 24 hours for the opportunistic yeasts, after 48 hours for the opportunistic filamentous fungi and after 120 hours for the dermatophytes. The MIC was defined as the lowest concentration of the compound causing 50\% inhibition of microorganism growth compared to the control without inhibitors.

\section{Mechanism-of-action assays}

The antifungal mechanism of action of naphthoquinone IVS320 (3a,10b-dihydro-1H-cyclopenta [b] naphtho [2,3-d] furan-5,10-dione)-dione) was evaluated using the yeast C. albicans strain ATCC 36232 as a model. The influence of IVS320 on the cell wall (sorbitol protection assay) and the effect of ergosterol on the cell membrane (ergosterol effect assay, $\mathrm{K}^{+}$efflux assay and leakage of substances absorbing at $260 \mathrm{~nm}$ ) were evaluated.

\section{Sorbitol protection assay}

We determined the MIC of IVS320 against C. albicans (ATCC 36232) following CLSI guidelines (from 100 to $0.20 \mu \mathrm{g} / \mathrm{mL}$ ) in the presence and absence of $0.8 \mathrm{M}$ sorbitol (Sigma-Aldrich), which acts as an osmotic support. The MICs were determined after 24 hours of incubation at $35^{\circ} \mathrm{C}[9,10]$.

\section{Ergosterol effect assay}

The MIC of IVS320 for C. albicans (ATCC 36232) was determined following CLSI guidelines in the presence and
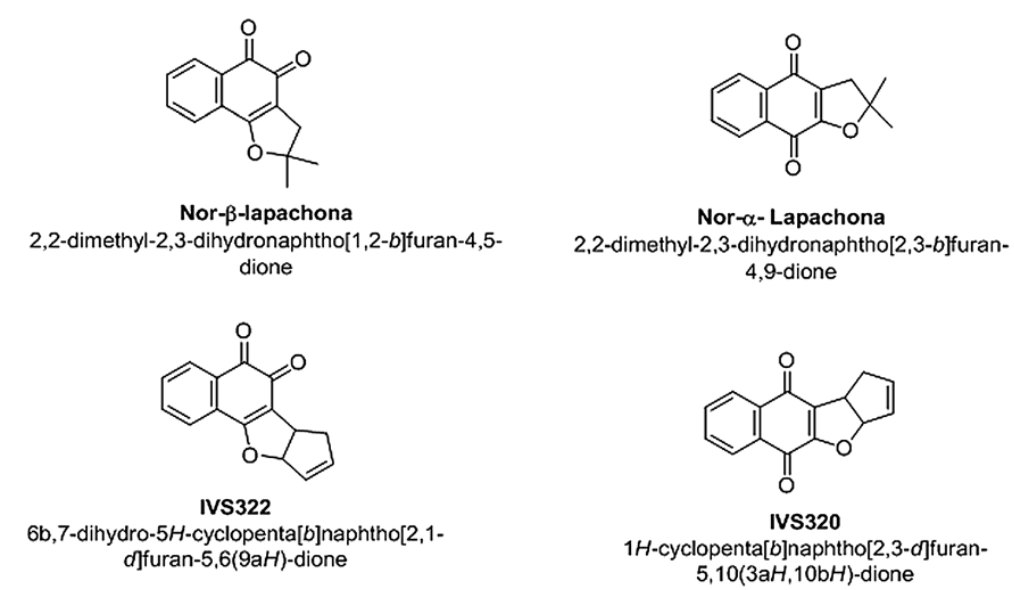

Figure 1 Structures of the naphthoquinones used in this study. 
Table 1 Microorganisms belonging to the INPA collection and from ATCC used in bioassays

\begin{tabular}{ccc}
\hline Group of organisms & Species $(\mathbf{n})$ & Lines of code \\
\hline Candida albicans $(n=1)$ & ATCC 36232 \\
Candida albicans $(n=10)$ & 56/04; 377/06; 839/10; 113/01; 07/10; 143/05; 62/08; 100/04; & 322/05; E2/09 \\
Opportunistic yeasts & Candida parapsilosis $(n=09)$ & U.1068; U.968/07; U.784/78; U.1047/08; 248/95; U1059/08; \\
U864/07; U840; U1018/08
\end{tabular}

absence of different ergosterol concentrations (SigmaAldrich) (200-800 $\mu \mathrm{g} / \mathrm{mL})$, as previously described $[10,11]$. Amphotericin B was used as a control in this assay. The MICs were determined after 24 hours of incubation at $35^{\circ} \mathrm{C}$.

\section{Potassium efflux assay}

C. albicans (ATCC 36232) was grown for 18 hours at $35^{\circ} \mathrm{C}$ in RPMI medium. The cells were washed and resuspended to a concentration of $2.5 \times 10^{3}$ cells $/ \mathrm{mL}$ in deionized water, and $1 \mathrm{~mL}$ of this suspension was incubated with IVS320 at the MIC concentration $(50 \mu \mathrm{g} / \mathrm{mL})$ in test tubes at $35^{\circ} \mathrm{C}$ for various time periods [12]. C. albicans incubated with deionized water only was used as a control. After centrifugation, the amount of $\mathrm{K}^{+}$released into the supernatant was measured using an atomic absorption spectrophotometer (AA Spectrophotometer 2380, PerkinElmer).

\section{Test for leakage of substances absorbing at $260 \mathrm{~nm}$}

C. albicans (ATCC 36232) was grown with shaking at $35^{\circ} \mathrm{C}$ until the early stationary phase (18 hours of growth) in RPMI. After incubation, C. albicans cells were washed and resuspended in MOPS buffer $(0.16 \mathrm{M}$, $\mathrm{pH}$ 7.0). Microtubes (final volume $500 \mu \mathrm{L}$ ) containing an inoculum of $5 \times 10^{4}$ cells $/ \mathrm{mL}$ and $1 \times$ or $4 \times$ MIC concentrations of IVS320 were incubated for 6 hours. After 1, 2,4 or 6 hours of incubation, the microtubes were centrifuged ( $5 \mathrm{~min}$ at 3,000 rpm), and the absorbance of the supernatants $(100 \mu \mathrm{L})$ was measured at $260 \mathrm{~nm}$ (Gene Quant DNA/RNA Eppendorf). In this assay, the absorbance due to leakage from cells treated with $\mathrm{HClO}_{4}$ $\left(1.2 \mathrm{M}, 100^{\circ} \mathrm{C}, 30 \mathrm{~min}\right)$ was considered $100 \%[10,13]$.

\section{Results}

\section{Antifungal activity of new naphthoquinones}

To investigate the antifungal potential of synthetic naphthoquinones, the MIC of each compound was determined against 89 fungal cultures, including opportunistic yeasts, dermatophytes and opportunistic filamentous fungi (Table 1). The compound designated IVS320 (3a,10b-dihydro-1Hcyclopenta [b] naphtho [2,3-d] furan-5,10-dione)-dione) presented the lowest MICs for all the tested cultures and was particularly active against dermatophyte fungi and yeasts from the genus Cryptococcus (Table 2). Regarding dermatophyte fungi, the mean MIC ranged from 5-28 $\mu \mathrm{g} / \mathrm{mL}$; against Cryptococcus spp., the mean $\mathrm{MIC}$ ranged from $3-5 \mu \mathrm{g} / \mathrm{mL}$.

\section{Investigation of the mechanism of action of IVS320 against C. albicans ATCC 36232 Action on the cell wall}

A sorbitol protection assay was conducted to determine the influence of IVS320 on the integrity of the fungal cell wall. In this assay, MIC determinations for IVS320 against C. albicans ATCC 36232 were carried out in parallel in the presence and absence of sorbitol $(0.8 \mathrm{M})$, which is an osmotic protectant used for the stabilization of fungal protoplasts. If a compound negatively interferes with the fungal cell wall, it will shift the MIC to a higher value in the presence of osmotic support [9]. The MIC of IVS320 did not change in the presence of sorbitol $(50 \mu \mathrm{g} / \mathrm{mL})$ after 72 hours of incubation, which suggests that IVS320 does 
Table 2 Minimum inhibitory concentrations (MICs) of new naphthoquinones against different fungal species

\begin{tabular}{|c|c|c|c|c|c|c|c|c|c|c|c|}
\hline \multirow{3}{*}{ Group microorganism } & \multirow{3}{*}{ Culture $(n=89)$} & \multicolumn{2}{|c|}{ Nor-alfa } & \multicolumn{2}{|c|}{ Nor-beta } & \multicolumn{2}{|c|}{ IVS320 } & \multicolumn{2}{|c|}{ IVS322 } & \multicolumn{2}{|c|}{ ketoconazole } \\
\hline & & \multicolumn{10}{|c|}{ Minimum Inhibitory Concentration (MIC) $\mu \mathrm{g} / \mathrm{mL}$} \\
\hline & & GM & Range & GM & Range & GM & Range & GM & Range & GM & Range \\
\hline \multirow{4}{*}{ Yeasts opportunistic } & C. albicans $(n=10)$ & 66 & $6.3-100$ & 86 & $6.3-100$ & 35 & $3.1-50$ & 78 & $6,3-100$ & 1 & $0,125-2$ \\
\hline & C. parapsilosis $(n=10)$ & 50 & - & 75 & $25-100$ & 25 & $13-50$ & 86 & $25-100$ & 0,06 & - \\
\hline & C. neoformans $(n=05)$ & 15 & $12.5-50$ & 100 & 100 & 5 & $1,56-6,25$ & 56 & $25-50$ & - & - \\
\hline & C. gattii $(n=04)$ & 25 & $12.5-50$ & 100 & 100 & 3 & $1,56-6.25$ & 44 & $25-50$ & - & - \\
\hline \multirow{4}{*}{ Dermatophytes } & T. rubrum $(n=10)$ & 16 & $6.3-25$ & 19 & $6.3-100$ & 5 & $3,3-12,5$ & 10 & $6,3-25$ & 29 & $2-64$ \\
\hline & M. canis $(n=10)$ & 43 & $25-50$ & 30 & $12,5-100$ & 8 & $3,1-12,5$ & 24 & $3,1-100$ & 5 & $1-16$ \\
\hline & M. gypseum $(n=10)$ & 78 & $50-100$ & 67 & $25-100$ & 28 & $12,5-50$ & 122 & $50-200$ & 5 & $2-8$ \\
\hline & T. tonsurans $(n=10)$ & 35 & $12,5-50$ & 34 & $6.3-200$ & 8 & $3,11-25$ & 38 & $25-50$ & 1 & $0,5-4$ \\
\hline \multirow{2}{*}{ Filamentous opportunistic } & Fusarium sp. $(n=10)$ & 117 & $50-200$ & 67 & $25-100$ & 36 & $25-50$ & 103 & $50-200$ & 6 & $1-16$ \\
\hline & Aspergillus sp. $(\mathrm{n}=10)$ & 90 & $50-100$ & 75 & $50-100$ & 33 & $6,3-50$ & 85 & $50-100$ & 32 & $4-64$ \\
\hline
\end{tabular}

$G M=$ geometric mean; - test not performed, $\mathrm{n}=$ number of different isolates.

The geometric mean and range for each compound against each group of fungal species are reported.

not act by inhibiting the mechanisms that control cell wall synthesis.

\section{Action on ergosterol}

An ergosterol assay was used to determine whether IVS320 induces changes in the fungal membrane by interacting with ergosterol. This assay has been shown to identify compounds that bind ergosterol in fungal membranes and is based on the addition of exogenous ergosterol. A compound that has an affinity for ergosterol rapidly forms complexes with free ergosterol, thus preventing interactions with ergosterol in the fungal membrane; as a result, the MIC of the tested compound increases. The results showed that the MIC of IVS320 against $C$. albicans ATCC 36232 did not change in the presence of different concentrations (200 to $800 \mu \mathrm{g} / \mathrm{mL}$ ) of exogenous ergosterol (Figure 2), suggesting that IVS320 does not act by interacting with ergosterol. In contrast, there was a $4 \times \mathrm{MIC}$ increase with amphotericin $\mathrm{B}$, which is known to have a strong affinity for ergosterol and served as the positive control in this assay [14].

\section{Action on potassium efflux}

A potassium efflux test was conducted to evaluate whether compound IVS320 interferes with the osmotic balance of $C$. albicans (ATCC 36232). This assay is based on the fact that the cell membrane is responsible for maintaining intracellular $\mathrm{K}+$, so an increase in extracellular $\mathrm{K}+$ indicates cell membrane disruption. As shown in Figure 3, the efflux of $\mathrm{K}^{+}$from C. albicans (ATCC 36232) cells into the extracellular medium increased with IVS320 treatment, whereas the extracellular $\mathrm{K}^{+}$concentration in the control culture remained constant during incubation. The time course of $\mathrm{K}^{+}$efflux into the culture supernatant indicated that the permeability of the fungal membrane increased up to 4 hours.

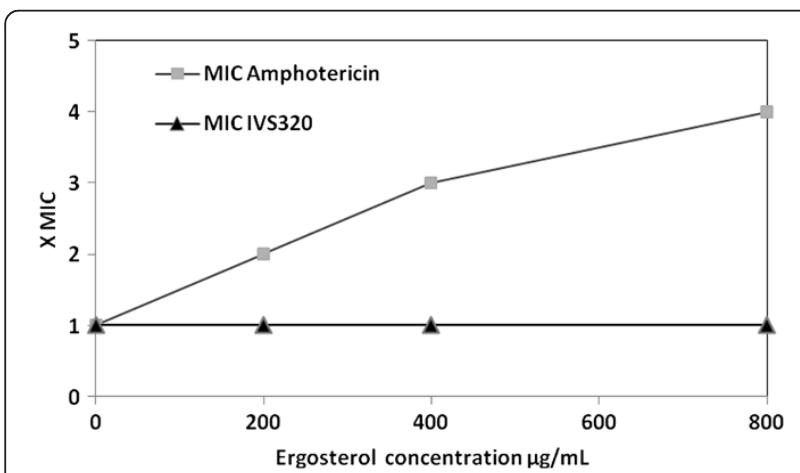

Figure 2 Effects of exogenous ergosterol $(200-800 \mu \mathrm{g} / \mathrm{mL})$ on the MIC of IVS320 and amphotericin B against C. albicans ATCC 36232. On the $y$-axis: $1=1 \times M I C, 2=2 \times M I C, 3=3 \times M I C, 4=4 \times M I C$.

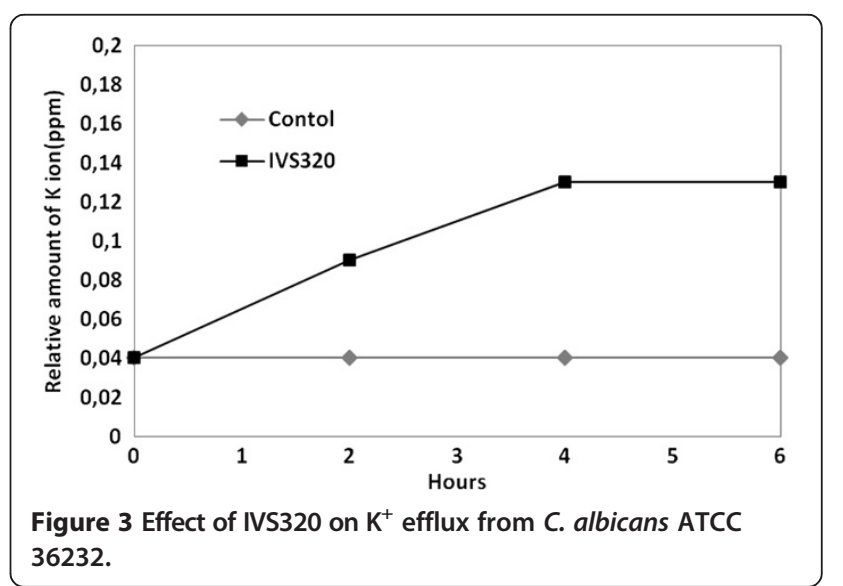




\section{Leakage of substances absorbing at $260 \mathrm{~nm}$}

The interference of IVS320 with the membrane of C. albicans ATCC 36232 was determined by evaluating the leakage of substances that absorb at $260 \mathrm{~nm}$ from the membrane. Membrane rupture causes the release/ leakage of intracellular components from the fungal cell, which can then be measured. Nucleotides, which exhibit a strong absorbance at $260 \mathrm{~nm}$, are among the components that can be monitored to detect leakage. IVS320 (1× MIC and $4 \times$ MIC) was added to cell suspensions of C. albicans, and the samples were examined after various time intervals $(1,2,4$ and 6 hours). The results showed that $1 \times$ IVS320 MIC caused increases of 6, 9, 17 and $21 \%$ at $1,2,4$ and 6 hours, respectively, compared to the perchloric acid control, which is considered to produce $100 \%$ cell leakage (Figure 4). Furthermore, the $4 \times$ MIC treatment caused a $2.6 \times$ increase in nucleotide leakage, resulting in 14, 25, 42 and $61 \%$ increases in leakage at 1, 2, 4 and 6 hours, respectively, compared to the perchloric acid control.

\section{Discussion}

The 1,4-naphthoquinone structure is common in various natural products and clinically used drugs that are associated with antifungal activity. Previous studies have demonstrated the potential of this class of compounds. Importantly, the work of Sassaki et al. [15] evaluated the antifungal activities of 1,4-naphthoquinone derivatives and obtained MICs of $8 \mu \mathrm{g} / \mathrm{mL}$ and $16 \mu \mathrm{g} / \mathrm{mL}$ against cultures of Candida albicans and Candida parapsilosis, respectively. Sheng et al. 2011 [5] studied structural changes and the structure/activity of 1,4-naphthoquinone, showing that the introduction of side chains containing sulfur, oxygen or nitrogen atoms at position $\mathrm{C} 2$ and/or C3 led to an increase in antifungal activity. These researchers also evaluated the activity of 17 compounds with different side chains and found three compounds that showed broad antifungal activity. One compound,

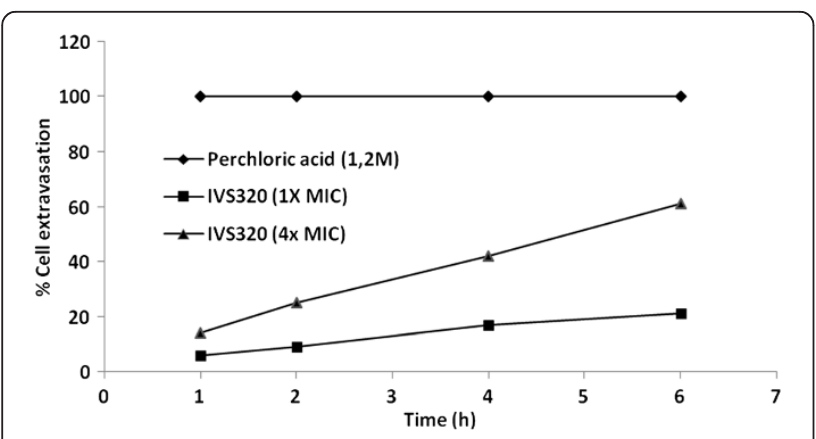

Figure 4 Leakage of substances absorbing at $260 \mathrm{~nm}$ from $C$. albicans ATCC 36232 incubated (1-6 hours) with $1 \times$ and $4 \times$ MICs for IVS320. [2-chloro-3-((4-hydroxyphenyl) amino) naphthalene-1,4dione], presented MICs of $3.12 \mu \mathrm{g} / \mathrm{mL}, 1.56 \mu \mathrm{g} / \mathrm{mL}$ and $0.78 \mu \mathrm{g} / \mathrm{mL}$ against Aspergillus fumigatus, C. albicans and $C$. neoformans, respectively. The antifungal potential of 1,4-naphthoquinone derivatives was also confirmed by Yamashita et al. [16] and Kategaonkar [17].

In the present work, all tested naphthoquinones exhibited antifungal activity. These results corroborate those of Freire et al. [6], who observed the inhibitory activity of these compounds against C. albicans, particularly Nor- $\alpha$. Nonetheless, these findings require confirmation across a large number of $C$. albicans isolates as well as other fungal classes. The results of the present study clearly demonstrate the potential of these antifungals against a large number of different isolates of pathogenic species.

IVS320 exhibited the lowest MIC against dermatophytes and Cryptococcus spp. These results are important given that this is the first study evaluating the antifungal action of this compound against these agents. The importance of new drugs for the treatment of dermatophytosis is highlighted by the fact that this disease affects approximately $40 \%$ of the world population, that only a small number of drugs are currently available for treatment, that azoles and allylamines have adverse gastrointestinal effects and that there is a high frequency of recurrence $[18,19]$. Amphotericin B and flucytosine are widely used for the treatment of cryptococcosis; however, the toxicity of both of these therapeutics is well described, and therapeutic failure is often observed [20]. Due to the robust results for IVS320, this naphthoquinone was selected for assessing its antifungal mechanism of action. A strain of Candida albicans (ATCC 36232) was selected due to the importance of this species in the epidemiology of fungal infections, and the use of an ATCC microorganism will facilitate reproduction of the work reported here [21].

IVS320 did not alter the structure of the fungal cell wall but did change the permeability of the cell membrane (efflux of $\mathrm{K}^{+}$and leakage of substances that absorb $260 \mathrm{~nm}$ ), which was not related to binding with ergosterol. These results are similar to those obtained by Emadi et al. [22], who evaluated the possible mechanism of action of bis-naphthoquinones and concluded that these compounds cause membrane depolarization.

Accordingly, the toxicity of IVS320 should be extensively evaluated against human cells, even though studies by Freire et al. [6] showed that this compound exhibited no significant hemolytic activity against mouse erythrocytes and no cytotoxicity against human fibroblasts $(\mathrm{NIH}$ $3 \mathrm{~T} 3$ ) at concentrations between 12.5 and $50 \mu \mathrm{g} / \mathrm{mL}$.

The results of the present study are relevant because they will motivate new in vivo research focusing on the development of new antifungal agents as alternatives for the treatment of ringworm and opportunistic mycoses. 


\section{Competing interests}

The authors declare that they have no competing interests.

\section{Authors' contributions}

JVBS: Study supervision, study concept and design, critical revision of the manuscript. VFF and ESL: Drafting of the manuscript, critical revision of the manuscript for important intellectual content. MPSBCF: Carried out the microbial assays, analysed the data and wrote the article. MFCC and FCS: Carried out drug synthesis. All authors read and approved the final manuscript.

\section{Author details}

${ }^{1}$ Universidade Federal do Amazonas, Manaus, AM, Brazil. 'Departamento de Química Orgânica, Universidade Federal Fluminense, Niterói, RJ, Brazil. ${ }^{3}$ Instituto Nacional de Pesquisa.da Amazônia, Laboratório de Micologia, Manaus, AM, Brazil.

Received: 19 March 2014 Accepted: 17 June 2014

Published: 6 July 2014

\section{References}

1. Borate HB, Sawargave SP, Chavan SP, Chandavarkar MA, lyer R, Tawte A, Rao D, Deore JV, Kudale AS, Mahajan PS, Kangire GS: Novel hybrids of fluconazole and furanones: design, synthesis and antifungal activity. Bioorg Med Chem Lett 2011, 21:4873-4878.

2. Ayati A, Falahati M, Irannejad H, Emami S: Synthesis, in vitro antifungal evaluation and in silico study of 3-azolyl-4-chromanone phenylhydrazones. Daru 2012, 20:46.

3. Ferreira VF, Ferreira SB, da Silva FDC: Strategies for the synthesis of bioactive pyran naphthoquinones. Org Biomol Chem 2010, 8:4793-4802.

4. Rahmoun NM, Boucherit-Otmani Z, Boucherit K, Benabdallah M, Villemin D, Choukchou-Braham N: Antibacterial and antifungal activity of lawsone and novel naphthoquinone derivatives. Med Mal Infect 2012, 42:270-275.

5. Sheng C, Zhang W: New lead structures in antifungal drug discovery. Curr Med Chem 2011, 18:733-766.

6. Freire CPV, Ferreira SB, de Oliveira NSM, Matsuura ABJ, Gama IL, da Silva FDC, de Souza MCBV, Lima ES, Ferreira VF: Synthesis and biological evaluation of substituted $\alpha$ - and $\beta$-2,3-dihydrofuran naphthoquinones as potent anticandidal agents. Med Che Comm 2010, 1:229.

7. National Committee for Clinical Laboratory Standards: Reference Method for Broth Dilution Antifungal Susceptibility Testing of Yeasts. Wayne, PA, USA: Approved Standard M27-A2; 2002.

8. National Committee for Clinical Laboratory Standards: Reference Method for Broth Dilution Antifungal Susceptibility Testing of Filamentous Fungi. Wayne, PA, USA: Approved Standard M38-A; 2002.

9. Frost DJ, Brandt KD, Cugier D, Goldman R: A whole-cell Candida albicans assay for the detection towards fungal cell wall synthesis and assembly. J Antibiot 1995, 48:306-310.

10. Carrasco H, Raimondi M, Svetaz L, Di Liberto M, Rodriguez MV, Espinoza L, Madrid A, Zacchino S: Antifungal activity of eugenol analogues. Influence of different substituents and studies on mechanism of action. Molecules 2012, 17:1002-1024.

11. Lunde CS, Kubo I: Effect of polygodial on the mitochondrial ATPase of Saccharomyces cerevisiae. Antimicrob Agents Chemother 2000, 44:1943-1953.

12. Hao G, Shi $Y-H$, Tang $Y-L$, Le G-W: The membrane action mechanism of analogs of the antimicrobial peptide Buforin 2. Peptides 2009, 30:1421-1427.

13. Tang $Y$-L, Shi $Y-H$, Zhao W, Hao G, Le G-W: Insertion mode of a novel anionic antimicrobial peptide MDpep5 (Val-Glu-Ser-Trp-Val) from Chinese traditional edible larvae of housefly and its effect on surface potential of bacterial membrane. J Pharm Biomed Anal 2008, 48:1187-1194.

14. Baran M, Borowski E, Mazerski J: Molecular modeling of amphotericin B-ergosterol primary complex in water II. Biophys Chem 2009, 141:162-168.

15. Sasaki $\mathrm{K}$, Abe $H$, Yoshizaki F: In vitro antifungal activity of naphthoquinone derivatives. Biol Pharm Bull 2002, 25:669-670.

16. Yamashita M, Kaneko M, Tokuda H, Nishimura K, Kumeda $Y$, lida A: Synthesis and evaluation of bioactive naphthoquinones from the Brazilian medicinal plant, Tabebuia avellanedae. Bioorg Med Chem 2009, 17:6286-6291.
17. Kategaonkar AH, Pokalwar RU, Sonar SS, Gawali VU, Shingate BB, Shingare MS: Synthesis, in vitro antibacterial and antifungal evaluations of new alpha-hydroxyphosphonate and new alpha-acetoxyphosphonate derivatives of tetrazolo [1, 5-a] quinoline. Eur J Med Chem 2010, 45:1128-1132.

18. Kathiravan MK, Salake AB, Chothe AS, Dudhe PB, Watode RP, Mukta MS, Gadhwe S: The biology and chemistry of antifungal agents: a review. Bioorg Med Chem 2012, 20:5678-5698.

19. Pereira F, Wanderley P: Growth inhibition and morphological alterations of Trichophyton rubrum induced by essential oil from Cymbopogon winterianus Jowitt ex Bor. Braz J 2011, 42:233-242.

20. Posteraro $B$, Posteraro $P$, Sanguinetti M: Update on antifungal resistance and its clinical impact. Curr Fungal Infect Rep 2013, 7:224-234.

21. Sifuentes-Osornio J, Corzo-León DE, Ponce-de-León LA: Epidemiology of invasive fungal infections in Latin America. Curr Fungal Infect Rep 2012, 6:23-34.

22. Emadi A, Ross AE, Cowan KM, Fortenberry YM, Vuica-Ross M: A chemical genetic screen for modulators of asymmetrical 2,2'-dimeric naphthoquinones cytotoxicity in yeast. PLoS One 2010, 5:e10846.

doi:10.1186/1476-0711-13-26

Cite this article as: Ferreira et al: Antifungal activity of synthetic naphthoquinones against dermatophytes and opportunistic fungi: preliminary mechanism-of-action tests. Annals of Clinical Microbiology and Antimicrobials 2014 13:26.

\section{Submit your next manuscript to BioMed Central and take full advantage of:}

- Convenient online submission

- Thorough peer review

- No space constraints or color figure charges

- Immediate publication on acceptance

- Inclusion in PubMed, CAS, Scopus and Google Scholar

- Research which is freely available for redistribution 